the surface of the medium over which they have travelled. When an agar plate is heavily inoculated in one spot and exposed to even illumination, the trichomes creep out evenly from all sides of the inoculum, for the most part following curved paths. Microscopic examination of the agar surface surrounding the inoculum on a plate several days old shows the presence of a large number of randomly oriented trichomes, the areas between them being covered with a network of curved tracks (Fig. 1). However, if the agar is initially subjected to tension (by laying a strip over a glass rod, for example), a markedly different pattern of movement develops. The trichomes move only in straight lines parallel to the applied stress, all migration from the inoculum at right-angles to the stress being prevented. On microscopic examination the trichomes are found to be rigidly oriented with their long axes parallel to the stress, and the tracks appear as a series of beautifully parallel straight lines (Figs. 2 and 3). As the organisms reach areas of decreased tension a certain amount of disorientation makes its appearance, and those trichomes which succeed in reaching a completely unstressed region of the agar regain their liberty of movement, reverting to the normal random orientation and following curved paths. When trichomes pass from an area of tension to one of compression, their orientation changes by $90^{\circ}$. The elasticotactic behaviour of blue-green Algæ is similar in all respects to that of myxobacteria, but the former organisms provide more favourable material for study of the phenomenon, because of their relatively much greater size and their formation of tracks on the substrate.

Since blue-green Algæ and myxobacteria have long been considered to possess similar mechanisms of locomotion, the identity of elasticotactic response in the two groups is not a matter for surprise. It would be interesting to know whether micro-organisms the movement of which on solid surfaces is effected by radically different mechanisms (for example, diatoms and amœboid protists) also respond to this stimulus.

Bacteriological Laboratories, Indiana University.

${ }^{1}$ Jacobsen, H. C., Centr. Bakt., ii, 17, 53 (1907).

${ }^{2}$ Sergent, E., Ann. Inst. Pasteur, 20, 1005 (1906).

3 Sergent, E., Ann. Inst. Pasteur, 21, 842 (1907).

- Weiss, P., J. Exp. Zool., 68, 393 (1934).

s Stanier, R. Y., J. Bact., 44, 405 (1942).

\section{Genetics of Red Body Colour in Armadillidium vulgare}

Previous work $^{1,2}$ and also many unpublished results have shown that in the woodlouse Armadillidium vulgare Latr. red body colour and a colour pattern called type $D$ behave as simple autosomal dominants to the common black and grey types (the only complication being that in adult animals type $D$ is sex-limited to the female sex). Collinge $e^{3,4,5}$, however, has reported results which do not agree with mine in that he fails to find any segregations. I was inclined to believe that Collinge's results were due to his scoring animals before they were really old enough for the different colour types to be distinguished; for he had stated ${ }^{6}$ that, when he examined some young from the variety rufobrunneus (red) at just over three weeks old, no trace of red or brown coloration was apparent, and that, if he had not known their history, he would have identified them as young specimens of the variety plumbeus (grey- black). While it must be emphasized that in the majority of cases red colour does behave as a simple dominant, and that one does usually obtain good $1: 1$ and $3: 1$ segregations, I have recently obtained some results which confirm Collinge's observations.

The first unexpected result was brood 223 from the red, type $D$ female $G N$, which was collected pregnant from Four Went Ways. This brood consisted of 95 black animals and 0 reds. This, of course, can be explained if we assume that there is a recessive gene for red as well as a dominant. Vandel ${ }^{7}$ has, in fact, found recessive red types in Armadillidium vulgare. Segregation for type $D$ in brood 223 was normal, the 92 females consisting of 48 type $B$ (the common female colour pattern) and 44 Type $D$.

The second set of unexpected results started with the red, type $B$ female $A U$, also obtained already pregnant from Four Went Ways. Brood 185 from this female consisted of 15 red : 35 black. The animals from this brood were numbered $A U A$ to $A U F$, and their breeding behaviour is shown in the table below :

$\begin{array}{ll} & \text { Parents } \\ \text { Female } & \text { Male } \\ A U A \text { (red) } & \text { Brood } 185 \text { red male } \\ A U B & \text { (red) } \text { Brood } 185 \text { red male } \\ A U B & \text { (red) } \text { None since brood } 213 \\ A U C \text { (red) } & \text { Brood } 185 \text { red male } \\ A U C \text { (red) } & C R A \text { (black) } \\ A U D \text { (red) } & \text { Brood 185 red male } \\ A U D \text { (red) } & A Y A \text { (black) } \\ A U E \text { (red) } F M \text { (black) } \\ C D \text { (red) Pregnant when collected } \\ C U \text { (red) None since brood } 187 \\ C U \text { (red) } A U F \text { (red) }\end{array}$

Brood
number
212
213
240
214
237
215
245
238
187
230
239

\begin{tabular}{cc}
\multicolumn{2}{c}{$\begin{array}{c}\text { Segregation } \\
\text { Red }\end{array}$} \\
Black \\
22 & 0 \\
30 & 0 \\
51 & 0 \\
18 & 0 \\
0 & 3 \\
36 & 0 \\
0 & 33 \\
0 & 56 \\
15 & 19 \\
33 & 52 \\
53 & 0
\end{tabular}

It will be noticed first that red females from brood 185, mated with their own brothers, produce broods consisting of red animals only, and secondly that the same females when mated with unrelated black males produce broods consisting of black animals only. Both these facts would fit the hypothesis that the red colour of female $A U$ and her offspring was due to a recessive gene. This explanation, however, probably breaks down when we consider brood 239 . Female $C U$ was obtained from the Cambridge University Farm, and all other red animals from this locality have always been dominant reds. The segregations in broods 187 and 230 are thus probably due to female $C U$ being heterozygous for dominant red and to her having mated with a common black male. If this is so, then male $A U F$ appears to be homozygous for dominant red and not for recessive red.

The true explanation of the above results is not yet known, and it is obvious that one easy test, namely, to inbreed black animals from broods 185 , 238 and 245, remains to be done. On the other hand, the results may not be explainable on normal Mendelian lines, since it is already known ${ }^{1,2,8}$ that sex ratios in Armadillidium and other woodlice are peculiar. It is also interesting to note that the Four Went Ways population is peculiar in containing quite a number of intersexes, including the one described by Collinge ${ }^{9}$.

School of Agriculture, H. W. How ARD

\section{Cambridge.}

March 24.

1 Howard, H. W., J. Genet., 40, 83 (1940).

${ }^{2}$ Howard, H. W., J. Genet., 44, 143 (1942).

${ }^{3}$ Collinge, W. E., Nature, 154, 797 (1944).

- Collinge, W. E., Nature, 155, 670 (1945).

- Collinge, W. E., Nature, 157, 485 (1946).

- Collinge, W. E., Nature, 158, 776 (1944).

? Vandel, A., Bull. Zool., 79, 168 (1945).

- Vandel, A., Bull. Biol., 75, 316 (1941).

' Collinge, W. F., Nature, 157, 304 (1946). 